\title{
VARIAÇÕES DOS TOTAIS DE CHUVAS E TEMPERATURA DO AR NA BACIA DO RIO PANDEIROS, NORTE DO ESTADO DE MINAS GERAIS-BRASIL: ARTICULAÇÃO COM FATORES DE DIFERENTES NÍVEIS ESCALARES EM ÁREA DE TRANSIÇÃO CLIMÁTICA DE CERRADO PARA SEMIÁRIDO
}

\author{
JARDIM, Carlos Henrique - dxhenrique@gmail.com \\ Universidade Federal de Minas Gerais / UFMG
MOURA, Felipe Pereira - felipegeografia@hotmail.com Universidade Federal de Minas Gerais / UFMG

\begin{abstract}
RESUMO: As variações dos elementos do clima constituem-se em importante aspecto a ser compreendido e considerado no diagnóstico ambiental e planejamento das atividades humanas. Em vista disso, este artigo tem como objetivo apresentar os resultados das análises das variações de chuva e temperatura do ar, considerando a influência das massas de ar, topografia e uso do solo no interior e áreas limítrofes à bacia do rio Pandeiros, norte do estado de Minas Gerais-Brasil. Situada em área de transição climática, as médias anuais de temperatura e chuva indicam, respectivamente, $24,4^{\circ} \mathrm{C}$ e $826,5 \mathrm{~mm}$, com fortes desvios negativos (Estação Meteorológica INMET Januária-MG, $15^{\circ} 26^{\prime} 52^{\prime \prime} ;-44^{\circ} 21^{\prime} 58^{\prime \prime} ; 468 \mathrm{~m}$ ). O relevo caracteriza-se por formas planas e convexas sobre amplos interflúvios com baixo grau de entalhamento dos vales e altitudes médias entre 400-800 m. O uso do solo inclui áreas de pastagens, lavoura, silvicultura, biótopos naturais (cerrado e mata ciliar) e limitado equipamento urbano. Foram utilizadas séries temporais históricas de dados de temperatura e chuva (anual e mensal) obtidas de estações meteorológicas do Instituto Nacional de Meteorologia (INMET) para o segmento temporal entre 1961-2017 e dados obtidos em campo (2016-2018). A análise utilizou técnicas estatísticas básicas (médias, máximos e mínimos, agrupamento, tendências e desvio-padrão), climatologia sinótica, "análise rítmica" e microclimatológica e os resultados mostraram variações e desvios nos totais de chuva e temperatura e relação com modificações introduzidas na cobertura vegetal primitiva e uso do solo.
\end{abstract}

PALAVRAS-CHAVE: chuva, temperatura, topografia, uso do solo.

VARIATIONS OF RAIN TOTALS AND AIR TEMPERATURE IN THE PANDEIROS RIVER BASIN, NORTH OF THE STATE OF MINAS GERAIS-BRAZIL: ARTICULATION WITH FACTORS OF DIFFERENT SCALAR LEVELS IN A CLIMATE TRANSITION AREA FROM SAVANNAH TO SEMIARID

\begin{abstract}
Variations in climate elements constitute an important aspect to be understood and considered in the environmental diagnosis and planning of human activities. The objective of this article is to present the results of analyzes of rainfall and air temperature variations, considering the influence of air masses, topography and land use, in the interior and areas adjacent to the Pandeiros River Basin. Located in a climatic transition area, the annual averages of temperature and rain indicate, respectively, $24,4^{\circ} \mathrm{C}$ and $826,5 \mathrm{~mm}$, with strong deviations (INMET Meteorological Station JanuáriaMG, $-15^{\circ} 26^{\prime} 52^{\prime \prime},-44^{\circ} 21^{\prime} 58^{\prime \prime}, 468 \mathrm{~m}$ ). The relief is characterized by flat and convex forms on large hills with low degree of carving of the valleys and average altitudes between 400 and $800 \mathrm{~m}$. Land use includes areas of pasture, agriculture, forestry, natural biotopes (savannah and ciliary forest) and limited urban equipment. Historical time series of temperature and rain data (annual and monthly) obtained from meteorological stations of the National Institute of Meteorology (INMET) for the time segment between 1961-2017 and data obtained in the fieldwork (2016-2017) were used. The analysis used basic statistical techniques (mean, maximum and minimum, grouping, trends and standard deviation), synoptic climatology, "rhythmic analysis" and microclimatological and the results showed variations and deviations in total rainfall and temperature and relation with changes introduced in the primitive vegetation cover and land use.
\end{abstract}

KEYWORDS: Frosts, Serra da Mantiqueira, Atmospheric Systems 
VARIACIONES DE LOS TOTALES DE LLUVAS Y TEMPERATURA DEL AIRE EN LA BACIA DEL RIO PANDEROS, NORTE DEL ESTADO DE MINAS GERAIS-BRASIL: ARTICULACIÓN CON FACTORES DE DIFERENTES NIVELES ESCALARES EN ÁREA DE TRANSICIÓN CLIMÁTICA DE SAVANA PARA SEMIARIO

RESUMEN: Las variaciones de los elementos del clima se constituyen en un importante aspecto a ser comprendido y considerado en el diagnóstico ambiental y planificación de las actividades humanas. En este sentido, este artículo tiene como objetivo presentar los resultados de las análisis de las variaciones de lluvia y temperatura del aire, considerando la influencia de las masas de aire, topografia y uso del suelo, en el interior y áreas limítrofes a la cuenca del rio Pandeiros, norte del estado de Minas Gerais-Brasil, resultado del proyecto de investigación. En el área de transición climática, las medias anuales de temperatura y lluvia indican, respectivamente, $24,4^{\circ} \mathrm{C}$ y $826,5 \mathrm{~mm}$, con fuertes desvíos negativos (Estación Meteorológica INMET Januária-MG, -15²6'52", $44^{\circ} 21^{\prime} 58^{\prime \prime}, 468 \mathrm{~m}$ ). El relieve se caracteriza por formas planas y convexas sobre amplios interflúvios con bajo grado de entallado de los valles y altitudes medias entre $400-800 \mathrm{~m}$. El uso del suelo incluye áreas de pastos, labranza, silvicultura, biotopos naturales (caatinga, sabana y mata ciliar) y limitado equipamiento urbano. Se utilizaron series temporales históricas de datos de temperatura y lluvia (anual y mensual) obtenidas de estaciones meteorológicas del Instituto Nacional de Meteorología (INMET) para el segmento temporal entre 1961-2017 y datos obtenidos en campo (2016-2017). El análisis utilizó técnicas estadísticas básicas (medias, máximos y mínimos, agrupamiento, tendencias y desviación estándar), climatología sinóptica, "análisis rítmico" y microclimatológica y los resultados mostraron variaciones y desvíos en los totales de lluvia y temperatura y relación con modificaciones introducidas en la cobertura vegetal primitiva y el uso del suelo.

PALABRAS CLAVE: Iluvia, temperatura, topografía, uso del suelo.

VARIATIONS DES TOTAUX DE PLUIE ET DE LA TEMPÉRATURE DE L'AIR DANS LE BASSIN DE LA RIVIĖRE PANDEIROS, AU NORD DE L'ÉTAT DE MINAS GERAIS-BRÉSIL: ARTICULATION AVEC DES FACTEURS DE DIFFÉRENTS NIVEAUX SCALAIRES DANS UNE ZONE DE TRANSITION CLIMATIQUE DE SAVANA Ȧ SEMIARID

RÉSUMÉ: Les variations des éléments climatiques constituent un aspect important à comprendre et à prendre en compte dans le diagnostic environnemental et la planification des activités humaines. Compte tenu de cela, cet article vise à présenter les résultats de l'analyse des variations des précipitations et de la température de l'air, compte tenu de l'influence de masses d'air, la topographie et l'utilisation des terres, à l'intérieur et dans les zones bordant le bassin du Pandeiros, dans l'État du Minas Gerais, au nord du Brésil, à la suite d'un projet de recherche. Situé dans la zone de transition climatique, la température annuelle moyenne et précipitations indiquent, respectivement, $24,4^{\circ} \mathrm{C}$ et $826,5 \mathrm{~mm}$, avec déviations negatives importants (Station météorologique INMET Januária-MG, $-15^{\circ} 26^{\prime} 52^{\prime \prime},-44^{\circ} 21^{\prime} 58^{\prime \prime}, 468 \mathrm{~m}$ ). Le relief est caractérisé par des formes plates et convexes sur de grands interfluves avec un faible degré de sculpture des vallées et des altitudes moyennes entre 400 et $800 \mathrm{~m}$. L'utilisation des terres comprend les zones de pâturage, l'agriculture, la foresterie, les biotopes naturels (semi-aride, savane et forêt ciliaire) et l'équipement urbain. Ils ont utilisé des séries chronologiques de données de température et de pluie (mensuels et annuels) obtenus par les stations météorologiques de l'Institut National de Météorologie (INMET) au segment temporel entre 1961-2017 et mesures sur le terrain (2016-2017). L'analyse des techniques statistiques de base utilisées (moyenne, maximum et minimum, regroupement, tendances et déviations), climatologie synoptique, "analyse du rythme" et microclimatológica et les résultats ont montré des variations et déviations de précipitations totales et de la température et aux changements introduits par rapport à la végétation précoce et l'utilisation des terres.

PALABRAS CLAVE: pluie, température, topographie, utilisation des terres. 


\section{INTRODUÇÃO}

As transformações introduzidas no ambiente, como a remoção da cobertura vegetal primitiva, alteração na rede fluvial, instalação de equipamentos urbanos etc. produzem efeitos diversos, levando ao aumento ou redução da qualidade ambiental, justificando a necessidade de conhecimento científico acerca das interações entre meioambiente e organização social.

Evidentemente, não se trata da defesa de um ambientalismo descomprometido com a realidade como se fosse possível a implementação das diversas atividades humanas sem quaisquer impactos negativos, mas de contribuir para a compreensão da dinâmica ambiental e aliar esse conhecimento às diversas situações de intervenção, garantindo a manutenção dos processos naturais (formação dos solos, reposição de água nos aquíferos, conservação da biodiversidade etc.).

Nesse sentido é inevitável a questão: como o conhecimento produzido sobre os climas pode contribuir para o desenvolvimento social e, ao mesmo tempo, evitar e/ou atenuar os impactos ambientais negativos? Sob perspectiva geográfica, a questão proposta é (ou deveria ser) a finalidade última das pesquisas em geografia-climatologia. Estudar as características das massas de ar para compreender a dinâmica das massas de ar ou estudar o clima urbano para compreender suas características nos diferentes espaços urbanos remete o pesquisador para uma espécie de tautologia ou círculo vicioso destituído de propósito legítimo e, portanto, de pouco valor para o avanço do conhecimento científico e da sociedade. O conhecimento produzido, necessariamente, deve caminhar para a solução de problemas concretos, quer seja ele de ordem teórica, tecnológica, de ensino-aprendizagem etc., embutido num contexto de discussões sobre as interações com outros componentes do meio e sistemas ambientais.

Essa questão passa, também, pelo conhecimento das formas particulares de interações e de organização hierárquica dos fatores climáticos (relevo, solos, vegetação, cidades etc.), desde processos que atuam em biótopos florestais à escala humana até aqueles presentes em domínios da magnitude da Amazônia e do Cerrado brasileiros, abarcando cada um deles várias realidades regionais. Em diversos momentos de sua obra, mas particularmente em dois deles, Monteiro $(1978 ; 2000)$ traz para o debate elementos acerca da influência das massas de ar em interação com o relevo ao discutir sua importância na caracterização dos climas locais e regionais, sítios urbanos e grandeza relativa dos geossistemas, a partir de perspectiva escalar decrescente, no qual o insumo energético vinculase aos fatores de escala superior (níveis global e zonal) e os impactos ambientais nas escalas inferiores (mesoclimas, topoclimas e microclimas). A distribuição e organização do insumo energético é realizado nas escalas intermediárias (regional e local) pelos fatores ou controles climáticos (componentes do sistema). Desde a interação com mecanismos de larga escala em teleconexão (Oscilação Decadal do Pacífico, El Niño/La Niña etc.) até os efeitos de núcleos de aquecimento e formação de pontos de alagamento em centros urbanos, a variação qualitativa e quantitativa dos fatores e processos que organizam o clima propicia o surgimento de dinâmica singular ou ritmo climático (MONTEIRO, 1971) que afetam os diferentes espaços terrestres.

E da mesma forma que o geógrafo se preocupa em definir as escalas espaciais, há a necessidade de definir as escalas temporais. Steinke (2004, p.23) discute a respeito de variabilidade climática como "uma das formas de 
inconstâncias climáticas que, por sua vez, fazem parte das mudanças climáticas" incluindo períodos de curto prazo (horas, dias), sazonais (períodos úmidos e secos), interanuais (alguns anos) e decadais (vários anos). Paralelamente ao argumento da autora, a necessidade de se compreender os desvios na variação dos atributos climáticos, como reforça Monteiro (1971), é fundamental uma vez que os impactos negativos são amplificados quando os valores dos atributos climáticos se distanciam das médias.

Conforme discussão conduzida por Jardim (2017), a forma como são colocadas questões sobre mudanças climáticas, muitas vezes presente no discurso político-ambientalista atual, utiliza dados pontuais como sendo representativos de variações em macroescala, distorcendo a compreensão de estrutura hierárquica do clima.

Como caso real, dentre os inúmeros problemas ambientais no qual o clima configura como importante variável, destacam-se as alterações detectadas na variação dos atributos climáticos em função da transformação de componentes da paisagem primitiva (introdução de áreas de pastagem, lavoura, equipamentos urbanos etc.). Exemplo disso consta do trabalho de Assis (2010) sobre o clima urbano em Belo Horizonte: enquanto o "clima natural" acompanha de perto a configuração do relevo, definindo duas unidades locais (área planáltica da Serra do Curral e a depressão de Belo Horizonte), a adição do estrato urbano diversifica o clima em unidades menores em forma de mosaico. Padrão semelhante havia sido verificado anteriormente em São Paulo por Tarifa e Armani (2001a; 2001b), cuja integração com o estrato urbano adiciona novos componentes ao ambiente, inclusive com indícios de alteração do ritmo de variação dos elementos climáticos (AZEVEDO e TARIFA, 2001). Jardim e Silva (2017) compararam Belo Horizonte com a área urbana de Ibirité através de análise de tendência e correlação aplicada à variação temporal da temperatura do ar (1961-2014), constatando valores significativos para Belo Horizonte, indicativo do porte atual da cidade e da multiplicação das fontes de calor de origem antropogênica.

Em relação às chuvas, apesar de estreitamente ligada à dinâmica atmosférica (circulação das massas de ar), a variação temporal e espacial desse elemento está sujeita à influência de fatores ou controles em superfície, modulando sua abrangência, intensidade e impactos sobre o ambiente (duração e volume de chuva precipitada, frequência e intensidade de enchentes etc.). Autores como Fraga (2003) e Avila e Mattedi (2015) discutiram essa questão considerando essas interações no vale do rio Itajaí em Santa Catarina. Em 2008, por exemplo, uma série de catástrofes atingiu essa região em decorrência da persistência de chuvas intensas durante o mês de novembro, havendo, inclusive, quem defendesse sua relação com "mudanças climáticas", quando na verdade os problemas resultaram, conforme análise dos autores supracitados, da ineficaz interação entre sistema natural e social, associado a desmatamento em áreas de topo de vertente e localização de cidades em planícies de inundação do rio Itajaí. O desmatamento, nesse caso, favoreceu o escoamento superficial da água e, consequentemente, o trabalho erosivo sobre os solos, acompanhado de movimentos de massa nas áreas de maior declividade da bacia e rápida elevação na vazão dos rios, atingindo inúmeras cidades situadas nessas áreas. Outro exemplo concreto, semelhante ao descrito anteriormente, foi discutido por Conti (2001) sobre os impactos das chuvas em áreas da Serra da Mantiqueira drenadas pelo rio Paraíba do Sul entre os estados de São Paulo, 
Minas Gerais e Rio de Janeiro, comparando episódio recente do ano 2000 e outro do ano de 1949.

Portanto, como pode ser observado, os problemas apontados não são privilégio do tempo presente ou de localidades específicas, embora assuma características próprias nos diferentes espaços, e o aumento em sua recorrência e distribuição espacial guarda estreita relação com a ampliação do espaço ocupado (e modificado) pela ação humana sem respeitar a capacidade de suporte do meio.

Considerando os vários aspectos das diferentes problemáticas que afetam o meio, o propósito deste artigo foi trazer os resultados de pesquisa sobre a climatologia na bacia hidrográfica do rio Pandeiros, importante tributário do rio São Francisco em seu médio vale no norte do estado de Minas Gerais, também afetada por importantes alterações nas características da paisagem ligadas à introdução de lavoura, pastagens, silvicultura e equipamento urbano. Exemplo recente disso incluem alterações no sistema hidrológico da bacia desse rio, com a construção de reservatório d'água para fins de produção de energia elétrica, que modificou a dinâmica de sedimentação do rio, assoreando amplas extensões da sua foz e trazendo repercussões negativas sobre os ecossistemas fluviais de matas ripárias e reprodução da ictiofauna.

A fim de relacionar o clima com as mudanças que afetam o ambiente, foram consideradas as variações de temperatura do ar como indicador de alteração ambiental, dada sua estreita relação com as propriedades da superfície em termos de recepção de radiação solar e conservação/transmissão de calor, e de pluviosidade, associada à variabilidade das chuvas e desenvolvimento de processos erosivos.

As premissas que nortearam os resultados aqui apresentados consideraram as alterações introduzidas nas características de uso da terra e seu efeito cumulativo ao longo do tempo no quadro ambiental, bem como a distinção entre variações induzidas por processos naturais e antrópicos, detectadas a partir de variações e/ou tendências de curto, médio e longo prazo, por controles ou fatores em diferentes escalas espaciais.

\section{CARACTERIZAÇÃO DA ÁREA DE ESTUDO}

A área de estudo (figura 01) inclui a bacia hidrográfica do rio Pandeiros, tributário do rio São Francisco em sua porção de médio vale, abarcada em sua totalidade pelos municípios mineiros de Januária e Bonito de Minas. Segundo dados do IBGE (2016) o município de Januária (15²9' $16^{\circ}$ " S; 44 21' 43" O) possui área de $6.661,666 \mathrm{~km}^{2}$ e população de 65.463 habitantes, com densidade demográfica de $9,83 \mathrm{hab} . / \mathrm{km}^{2}$. Sua população está dividida entre a área urbana $(63,1 \%)$ e rural $(36,9 \%)$ e a economia volta-se para o setor de serviços e, secundariamente, indústria e agropecuária. O município de Bonito de

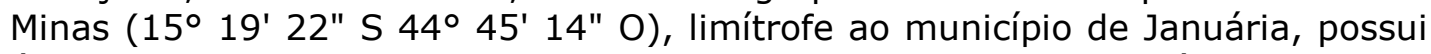
área de $3.905 \mathrm{~km}^{2}, 10.797$ habitantes e densidade demográfica de 2,77 $\mathrm{hab} . / \mathrm{km}^{2}$. A economia gira em torno do artesanato e agricultura. 


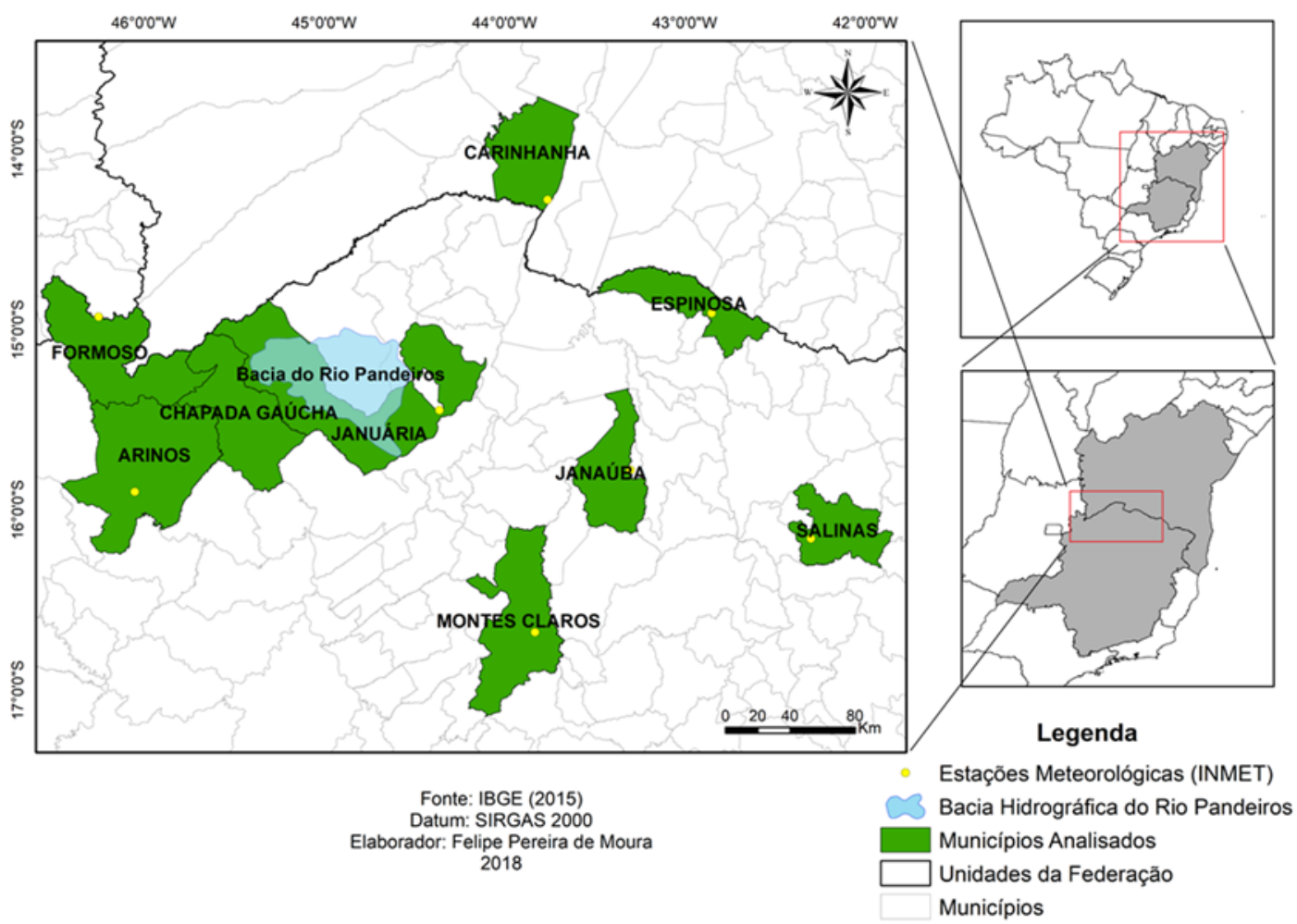

Figura 01 - Localização da bacia do rio Pandeiros e municípios próximos dotados de estações meteorológicas da rede oficial do Instituto Nacional de Meteorologia (INMET). Organização: Felipe Pereira de Moura.

O clima assinala transição de regime tropical quente semiúmido para semiárido, com 4-5 meses de seca, podendo chegar a 6 meses de seca (NIMER, 1989). De acordo com dados das Normais Climatológicas 1961-1990 (DNMET, 1992), as médias anuais de chuva e temperatura em Januária, próximo à foz do Rio Pandeiros (altitude: $468 \mathrm{~m}$ ), indicam, respectivamente, $826,5 \mathrm{~mm}$ e $24,4^{\circ} \mathrm{C}$, concentrados entre os meses de novembro e março.

O relevo inclui formas plano-onduladas com baixo grau de entalhamento dos vales, amplos interflúvios no baixo e médio vale e chapadões com topo plano e vertente retilíneas nas áreas de cabeceiras, com valores médios de altitude em torno de $800 \mathrm{~m}$.

A vegetação primitiva exibe características tanto do domínio das Caatingas quanto do Cerrado (incluindo mata ciliar) acrescida, atualmente, de um mosaico diversificado de unidades de uso do solo com vilarejos, áreas de lavoura, silvicultura e pastagem.

\section{MATERIAL E MÉTODOS}

Foram consultados dados das Normais Climatológicas 1961-1990 (DNMET, 1992) com a finalidade de obter um quadro geral de representação do clima na região. Posteriormente utilizaram-se as séries anuais de dados (19612017) obtidas das estações meteorológicas do Instituto Nacional de Meteorologia - INMET (www.inmet.gov.br) através do Banco de Dados Meteorológicos para Ensino e Pesquisa (BDMEP), situadas nos municípios de 
Arinos, Chapada Gaúcha, Espinosa, Formoso, Janaúba, Januária, Montes Claros e Salinas no estado de Minas Gerais e Carinhanha no estado da Bahia, com o objetivo de analisar a variabilidade das chuvas e da temperatura do ar.

Verificou-se a consistência dos dados eliminando-se os anos com mais de dois meses sem dados e substituindo os meses faltantes com dados de média simples aritmética daquele mês. Os dados foram tabulados e trabalhados através de procedimentos estatísticos básicos, utilizando-se do software Microsoft Excel (versão 2010).

Com os dados obtidos elaboraram-se tabelas e gráficos referentes ao acumulado de precipitação e os desvios em relação às médias. Para definição de anos secos, chuvosos e habituais, conforme Galvani et al. (2012), considerou-se o valor de desvio padrão que, somado ao valor médio de chuva do período, definiu o patamar dos "anos chuvosos" e, de forma semelhante, subtraindo o valor do desvio padrão da média estabeleceu-se o patamar dos "anos secos". Os anos "habituais" encontram-se entre esses dois patamares, aproximando-se das médias.

A construção de gráficos de Box Plot foi outro recurso utilizado para análise da variabilidade das chuvas. De acordo com Galvani e Luchiari (2012) a distribuição dos valores ocorre a partir da definição de quartis definido pelo valor da mediana: os dois quartis centrais e a mediana (a caixa central é dividida pela mediana) representam os valores próximos aos habituais, os prolongamentos lineares da caixa superior e inferior representam, respectivamente, os valores máximos e mínimos, que podem incluir ou representar de forma separada os valores extremos (outliers).

Os dados produzidos foram comparados, também, com informações relativas ao ambiente físico (relevo, latitude etc.) e atmosférico ligado à ação das massas de ar e em interação com mecanismos de larga escala em teleconexão.

Em relação aos dados de temperatura do ar foi aplicada a análise de regressão linear simples para a série temporal entre 1961-2016 visando detectar tendências e possíveis correlações $(R)$ entre a variação dos atributos (temperatura) e as transformações nas características de uso da terra.

A análise local da temperatura contou com dados horário-diários das estações meteorológicas de Januária $\left(-15,448089170 ;-44,36631333^{\circ} ; 468 \mathrm{~m}\right)$ e Chapada Gaúcha $\left(-15,300159^{\circ} ;-45.617431^{\circ} ; 873 \mathrm{~m}\right)$, utilizadas, também, como controle local das variáveis climáticas. Entre essas duas estações, no interior da bacia do rio Pandeiros, foram obtidos, também, dados em campo a partir de duas estações meteorológicas portáteis (Davis Vantage Pro 2) e de três pontos com registradores automáticos (datalogger, marca Akso AK 172) instalados em área de pastagem manejada e interior de formações florestais de mata ciliar e transição pastagem-cerrado, durante segmentos temporais entre os anos de 2016-2017.

A análise dos dados de temperatura e umidade relativa do ar utilizou recursos estatísticos básicos, incluindo análise de tendência e correlação para as séries temporais anuais entre 1961-2017. A análise dos dados horário-diários obtidos em campo entre 2016-2017 apoiou-se no cálculo de médias, identificação de valores máximos e mínimos médios e absolutos e de amplitudes horário-diárias, relacionadas às características de tempo, topografia, uso do solo e cobertura vegetal, considerando os termos de balanço da radiação de ondas 
curtas (radiação solar) e longas (calor) influenciadas pela dinâmica das massas de ar. As condições atmosféricas (sucessão das massas de ar) foram inferidas a partir do exame de imagens de satélite meteorológico (www.cptec.inpe.br) e cartas sinóticas (www.mar.mil.br).

\section{RESULTADOS E DISCUSSÃO}

De acordo com dados da estação meteorológica de Januária (DNMET, 1992) a temperatura não mostra grandes variações anuais (média: $24,2^{\circ} \mathrm{C}$; média das máximas: $30,9^{\circ} \mathrm{C}$; média das mínimas: $18,4^{\circ} \mathrm{C}$ ) em função da latitude e advecção de calor pelas massas de ar Equatorial Continental (mEc) e Tropical Atlântica (mTa) conforme descrição de Borsato (2016), cujas fontes de origem remetem a áreas que experimentam elevado saldo anual de energia em todos os meses do ano. Entretanto, em microescala, através de alterações na cobertura vegetal primitiva e introdução de novos componentes no ambiente (lavoura, pastagem, equipamento urbano etc.) foi possível detectar alterações nas variações desse atributo.

A aplicação da técnica de regressão linear à série temporal de dados médios anuais de temperatura traz indícios que podem ser interpretados como tendência de aumento da temperatura do ar, desencadeado tanto por fatores naturais quanto relacionados à influência antrópica. De acordo com a figura 02 a temperatura média máxima e mínima anual e o valor de correlação $(R)$ para o período de $1961-2017$ em Januária foi, respectivamente, de $31,5^{\circ} \mathrm{C}$ e $18,3^{\circ} \mathrm{C}$ e 0,68 e 0,21 .

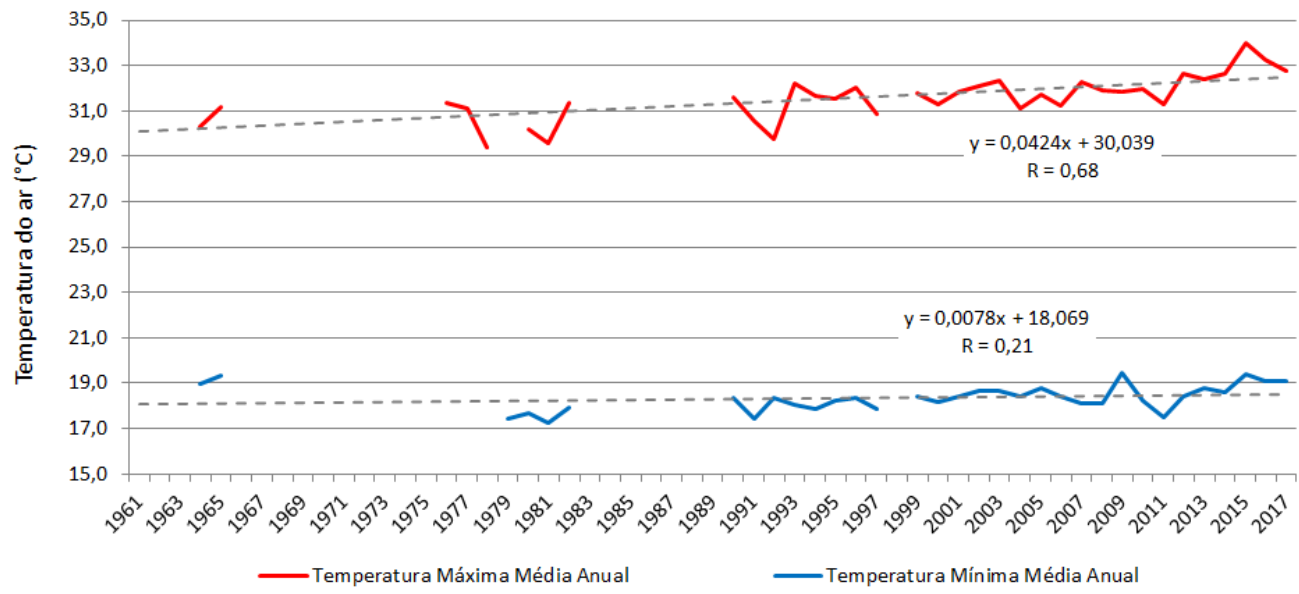

Figura 02 - Variação anual e tendência da temperatura média do ar máxima e mínima para os períodos de 1961-2017 em Januária-MG. Organização: Carlos H. Jardim.

Embora as temperaturas mínimas se constituam num indicador mais confiável em relação às temperaturas máximas, em função de sua relação estreita com a conservação e produção adicional de calor no ambiente, a explicação para a tendência geral de aumento estaria relacionada à atual fase do ciclo de aquecimento das águas do Oceano Pacífico (Oscilação Decadal do Pacífico o ODP), atuante desde meados dos anos 1970 até atingir o auge ao 
final dos anos 1990 conforme Molion (2005) e discussão de Silva et al. (2017). E a série de dados analisada encontra-se em grande parte inserida nesse período.

Por outro lado, essa variação natural não explica totalmente as variações encontradas. Para outras localidades no estado de Minas Gerais, de acordo com Vianello et al. (2008) e Jardim e Silva (2016), verifica-se em quase todos os casos baixo valor ou valor nulo de correlação (sem qualquer indicativo de tendência), a não ser naquelas localidades dotadas de área urbana expressiva, com maior valor de correlação, principalmente nas temperaturas mínimas, fato também observado por Assis (2010) em Belo Horizonte.

Apesar da discrepância entre os valores de correlação e baixa representatividade do valor relacionado à variação da temperatura média das mínimas, as variações de temperatura obtidas em ambientes microclimáticos são expressivas e indicam claramente maior disponibilidade de calor sensível e menor aporte de umidade para o ar através da evapotranspiração em áreas de pastagem e em ambiente de transição entre áreas rurais e urbanas.

Os valores médios, máximos e mínimos de temperatura e umidade relativa do ar obtidos na área de mata ciliar do rio Pandeiros no período de 20/10 a 11/12/2016 (tabela 01) mostram valores médios inferiores de temperatura do ar quando comparados àqueles obtidos em área de pastagem e com a estação meteorológica do INMET de Januária.

Tabela 01 - Média geral e valores absolutos das variações diárias da temperatura e umidade relativa do ar no período de 20/10 a 11/12/2016 (Org.: Carlos H. Jardim).

\begin{tabular}{l|c|c|c|c|c|c}
\hline & \multicolumn{2}{|c|}{ Mata ciliar (459,5 m) } & \multicolumn{2}{|c|}{ Pastagem (488 m) } & Januária INMET (468 m) \\
\cline { 2 - 6 } & Temp. $\left({ }^{\circ} \mathrm{C}\right)$ & UR (\%) & Temp. $\left({ }^{\circ} \mathrm{C}\right)$ & UR (\%) & Temp. $\left({ }^{\circ} \mathrm{C}\right)$ & UR (\%) \\
\hline Média geral & 25,4 & 65 & 26,4 & 66 & 26,8 & 64 \\
\hline Max. Absol. & 36,5 & 92 & 37,7 & 96 & 38,2 & 98 \\
\hline Min. Absol. & 17,2 & 14 & 19,3 & 16 & 20,2 & 16 \\
\hline Dif. Máx. Mín. & 19,3 & 78 & 18,4 & 80 & 18,0 & 82 \\
\hline
\end{tabular}

Em outro momento (tabelas 02 e 03) a comparação foi obtida com valores novamente do posto da mata ciliar, no limite entre cerrado arbóreo e pastagem e das estações meteorológicas do INMET de Januária e Chapada Gaúcha. 
Tabela 02 - Médias e valores absolutos das variações diárias da temperatura e umidade relativa do ar no período de 16/12/2016 a 30/04/2017 (Org.: Carlos H. Jardim).

\begin{tabular}{|c|c|c|c|c|c|c|}
\hline & \multicolumn{2}{|c|}{$\begin{array}{l}\text { Mata Ciliar } \\
(459,5 \mathrm{~m})\end{array}$} & \multicolumn{2}{|c|}{$\begin{array}{c}\text { Cerrado-Pastagem } \\
(799 \mathrm{~m})\end{array}$} & \multicolumn{2}{|c|}{$\begin{array}{c}\text { Januária INMET } \\
(468 \mathrm{~m})\end{array}$} \\
\hline & Temp. $\left({ }^{\circ} \mathrm{C}\right)$ & UR (\%) & Temp. $\left({ }^{\circ} \mathrm{C}\right)$ & UR (\%) & Temp. $\left({ }^{\circ} \mathrm{C}\right)$ & UR (\%) \\
\hline Média geral & 24,9 & 65 & 24,1 & 62 & 26,2 & 66 \\
\hline Máx. Absol. & 35,9 & 92 & 37,7 & 92 & 36,4 & 98 \\
\hline Mín. Absol. & 17,0 & 18 & 15,3 & 14 & 16,8 & 23 \\
\hline Dif. Máx. Mín. & 18,9 & 74 & 22,4 & 78 & 19,6 & 75 \\
\hline Méd. Máx. Diárias & 31,5 & 83 & 32,4 & 81 & 32,9 & 89 \\
\hline Méd. Mín. Diárias & 20,2 & 40 & 18,6 & 36 & 20,3 & 40 \\
\hline Dif. Máx. Mín. & 11,3 & 43 & 13,8 & 45 & 12,6 & 49 \\
\hline
\end{tabular}

Tabela 03 - Médias e valores absolutos das variações diárias da temperatura e umidade relativa do ar no período de 03/05 a 21/09/2017 (Org.: Carlos H. Jardim).

\begin{tabular}{l|c|c|c|c|c|c}
\hline & $\begin{array}{c}\text { Mata Ciliar } \\
(459,5 \mathrm{~m})\end{array}$ & $\begin{array}{c}\text { Januária INMET } \\
(468 \mathrm{~m})\end{array}$ & $\begin{array}{c}\text { Chapada Gaúcha INMET } \\
(873 \mathrm{~m})\end{array}$ \\
& Temp. ( $\left.{ }^{\circ} \mathrm{C}\right)$ & UR (\%) & Temp. $\left({ }^{\circ} \mathrm{C}\right)$ & UR (\%) & Temp. $\left({ }^{\circ} \mathrm{C}\right)$ & UR (\%) \\
\hline Média geral & 22,2 & 53 & 23,4 & 48 & 21,4 & 47 \\
\hline Máx. Absol. & 35,3 & 94 & 35,9 & 93 & 32,8 & 90 \\
\hline Mín. Absol. & 9,4 & 8 & 11,5 & 12 & 11,2 & 12 \\
\hline Dif. Máx. Mín. & 25,9 & 86 & 24,4 & 81 & 21,6 & 88 \\
\hline
\end{tabular}

As diferenças de temperatura do ar em termos de valores absolutos, comparando o ambiente de mata ciliar com a área de pastagem, superaram frequentemente valores de $2,0^{\circ} \mathrm{C}, 3,0^{\circ} \mathrm{C}$ ou $4,0^{\circ} \mathrm{C}$ em situações horário-diárias (sempre inferiores na mata ciliar). $\mathrm{O}$ excedente de calor produzido em ambiente aberto de pastagem, decorrente do maior grau de insolação sobre a superfície parcialmente desprovida de vegetação, é adicionado ao excedente de calor próprio da latitude da área de estudo $\left(15,5^{\circ} \mathrm{Sul}\right)$ forçando, com relativa frequência, a elevação da temperatura para valores superiores a $35,0^{\circ} \mathrm{C}$. As superfícies, nesse caso, funcionam como fontes passivas de calor, cuja carga radiativa fica concentrada nos primeiros centímetros da superfície em função de sua opacidade e ineficaz processo de propagação de calor (por contato molecular) para as camadas mais profundas de solo, transferindo o forte excedente de calor para o volume de ar sobrejacente mais frio, o que explica, também, além da elevada recepção de radiação solar durante o dia, a forte perda radiativa de calor no período noturno decorrente das condições de relativa estabilidade atmosférica, quase ausência de obstáculos frente à saída de calor e menor influência do vapor dágua no efeito estufa natural (os valores das mínimas foram, em geral, inferiores nos locais fora do ambiente de mata ciliar).

No ambiente de mata ciliar o adensamento de elementos arbóreos do estrato vegetal e a obstrução da radiação solar pelo dossel foliar limita o saldo de energia e, portanto, de disponibilidade de calor sensível, ao mesmo tempo em que atenua a contribuição externa de advecção de calor das áreas adjacentes. Outro elemento importante nesse ambiente refere-se ao aporte de 
vapor e umidade oriunda da evapotranspiração vegetal, evaporação da água dos solos e serrapilheira e evaporação das águas do rio Pandeiros, contribuindo com a redução do estoque de calor sensível disponível no meio pela conversão de calor sensível em calor latente envolvido na evaporação. Deve-se mencionar, também, o papel da serrapilheira na redução da transmissão de calor em profundidade no solo (o tecido vegetal é péssimo transmissor e conservador de calor) e o consumo de parte da energia solar nos processos metabólicos das plantas, reduzindo a disponibilidade dessa fração energética para o ambiente.

O elevado valor de calor específico do povoamento vegetal e da serrapilheira de $0,8 \mathrm{cal} / \mathrm{cm}^{2} .{ }^{\circ} \mathrm{C}$ em comparação ao concreto com $0,2 \mathrm{cal} / \mathrm{cm}^{2} .{ }^{\circ} \mathrm{C}$ (GEIGER, 1961, p.268) e a baixa condutividade de calor pelo tecido vegetal e serrapilheira que na água equivale a $0,57 \mathrm{~W} / \mathrm{m} . \mathrm{K}$ e nas rochas em $2,9 \mathrm{~W} / \mathrm{m} . \mathrm{K}$ (ARYA, 2001), também se constituem em fatores adicionais que atenuam as variações de temperatura no ambiente de mata ciliar.

A análise comparativa das médias e medianas das séries históricas dos dados de precipitação para o período de 1964-2016 (51 anos) dos oito municípios selecionados e de suas respectivas normais climatológicas (19611990) permitiu a identificação de significativas diferenças entre as localidades, conforme apresentado na tabela 4 . Os municípios com os maiores valores de médias observadas foram Formoso e Arinos, com 1208,7 mm e 1164,5 mm, respectivamente. Quando se observa as normais climatológicas 1961-1990 (DNMET, 1992), esses municípios se mantem, também, com os maiores totais anuais (Formoso: 1176,0 mm; Arinos, 1275,0 mm).

Tabela 4 - Valores das Medianas e Médias de precipitação $(\mathrm{mm})$ para o período de 1964 - 2016 e as Normais Climatológicas 1961-1990 e 1981-2010 (Org.: Carlos H. Jardim).

\begin{tabular}{|c|c|c|c|c|}
\hline & $\begin{array}{c}\text { Mediana } \\
(1964-2016)\end{array}$ & $\begin{array}{c}\text { Média } \\
(1964-2016)\end{array}$ & $\begin{array}{c}\text { Norm. Climatol. } \\
(1961 \text { - 1990) }\end{array}$ & $\begin{array}{c}\text { Norm. Climatol. } \\
(1981 \text { - 2010) }\end{array}$ \\
\hline Januária & 778,2 & 903 & 826,5 & 948,3 \\
\hline Montes Claros & 833,7 & 1019,6 & 1086,4 & 1086,4 \\
\hline Carinhanha & 672,5 & 798,9 & 813,7 & 757,6 \\
\hline Espinosa & 540 & 681,7 & 745 & 739,6 \\
\hline Janaúba & 601,3 & 765,3 & - & 780,7 \\
\hline Salinas & 700,3 & 847,1 & 846,1 & 877,2 \\
\hline Arinos & 1079,8 & 1164,5 & 1275,2 & 1180,6 \\
\hline Formoso & 1120,3 & 1208,7 & 1176 & 1225,7 \\
\hline
\end{tabular}

Entre os municípios mineiros analisados, Arinos e Formoso são os únicos situados fora da mesorregião Norte de Minas, estabelecida pelo IBGE. Estão localizados mais ao interior do continente, ou seja, mais a oeste em relação aos demais municípios, pertencendo à mesorregião Noroeste de Minas. Trabalhos como o de Sant'Anna Neto (2005), em que foram elaborados mapas de distribuição das chuvas na região sudeste do país destacam maior aporte de chuva sobre essa região quando comparado ao norte do estado, conforme constatado. Essa diferença se deve em razão do posicionamento mais a oeste do estado, da maior intensidade na atuação das ZCAS, em sua orientação noroeste-sudeste, bem como da formação de linhas de instabilidade, fornecendo à região em que se inserem maior aporte de chuvas em comparação com os 
demais municípios. Nimer (1989) destaca influência dessas linhas de instabilidade, no período compreendido entre a primavera e o outono, com mais intensidade no decorrer do verão, quando ocorre no interior do Brasil, devido ao aquecimento do continente e consequente decréscimo geral da pressão atmosférica. Segundo o autor, a origem desse sistema "parece estar ligada ao movimento ondulatório que se verifica na frente polar ao contato com o ar quente da zona tropical" (NIMER, 1989, p.273). Ainda conforme Nimer, a formação desse sistema desencadeia chuvas e ventos vindos de oeste a noroeste, gerando chuvas principalmente sobre os estados do Mato Grosso, Goiás e Minas Gerais, acarretando, devido à orientação do sistema, em maior atuação na região noroeste de Minas Gerais, embora não se limite a essa região. Desse modo, observa-se a influência da dinâmica climática do centro-oeste brasileiro sobre a região noroeste do estado de Minas Gerais.

O município de Montes Claros, pertencente à mesorregião Norte de Minas, situa-se mais ao sul em comparação às demais localidades, apresentando significativos valores para os totais anuais de chuva, com média anual de precipitação acumulada de $1019,6 \mathrm{~mm}$ para o período de $1964-2016$, pouco inferior à normal climatológica para o período de 1961-1990 que é de 1086,4 $\mathrm{mm}$. Em consequência do posicionamento geográfico mais ao sul, sistemas produtores de chuva, como os sistemas frontais, atuam com maior intensidade sobre o município, perdendo força na medida em que avançam para latitudes menores. Sant'Anna Neto (2005, p.47) destaca a variação latitudinal como característica da variação dos parâmetros climáticos para a região sudeste, uma vez que:

[...] os climas latitudinais da região Sudeste, apesar de tipicamente tropicais, apresentam significativas variações térmicas e pluviométricas em grande parte explicadas pela grande extensão norte/sul que se produz, à medida que a latitude aumenta, diminui a temperatura e, aumentam os totais anuais de precipitação. (SANT'ANNA NETO, 2005, p.47).

Montes Claros também está situado em área de relevo deprimida, o que afeta de forma negativa o volume de precipitação (NIMER, 1989), similar ao que ocorre com o município de Januária e, mesmo apresentando média de precipitação anual superior em relação a esse município, autores como Nimer (1989) e Sant'Anna Neto (2005) apontam que a região de Montes Claros apresenta características típicas do semiárido, assim como a própria região de Januária e a região do Vale do Jequitinhonha.

Espinosa e Janaúba aparecem como os municípios mineiros com menores valores de precipitação, com médias anuais de $681 \mathrm{~mm}$ e 765,3 mm, respectivamente. O município de Espinosa faz fronteira com o sul do estado da Bahia, sendo cortado pela Serra do Espinhaço, situando-se na vertente oeste. Carinhanha também apresenta um dos menores valores de precipitação anual, com média de 798,9 mm. Esse município está localizado ao sul do estado da Bahia, na divisa com e norte de Minas Gerais, na porção sul do nordeste brasileiro (NEB), situado em área deprimida no vale do São Francisco.

Kayano e Andreoli (2009, p.216) argumentam que os sistemas frontais (SFs) são importantes fenômenos geradores de precipitação durante o período 
úmido, entre a primavera e verão do hemisfério sul (HS), na região sul do nordeste brasileiro (NEB):

A máxima precipitação de novembro a março, com um pico em dezembro do sul do NEB, é ocasionada pela incursão de SFs e seus remanescentes entre $5^{\circ} \mathrm{S}$ e $18^{\circ} \mathrm{S}$, que interagem com a convecção local. Oliveira (1986) mostrou que os SFs podem interagir com a convecção local, especialmente na primavera e no verão do HS, quando os SFs apresentam ampla penetração continental, uma condição apontada como necessária para a interação. Nesse trabalho foi mostrado também que essa condição se manifesta entre $15^{\circ} \mathrm{S}$ e $20^{\circ} \mathrm{S}$, com a nebulosidade associada de noroeste para sudeste ao longo de uma faixa que, posteriormente, foi chamada de Zona de Convergência do Atlântico Sul. (KAYANO e ANDREOLI, 2009, p.216).

Os municípios de Januária e Salinas apresentaram valores mais centrais em relação ao conjunto dos municípios, com médias de precipitação de 903,0 $\mathrm{mm}$ e $847,1 \mathrm{~mm}$, respectivamente. Percebe-se que neste caso o efeito da continentalidade não parece diferenciar esses municípios no que se refere aos totais pluviométricos, uma vez que Januária está a $234,5 \mathrm{~km}$ em linha reta a noroeste de Salinas, ou seja, mais para o interior do continente. Conforme Ayoade (2011, p.164) as "áreas próximas dos grandes corpos hídricos recebem mais precipitação do que os interiores dos continentes, que se localizam distantes das fontes oceânicas de suprimento de umidade". Entretanto, a relação entre o volume de precipitação nesses municípios está ligada a aspectos dinâmicos da circulação das massas de ar. Salinas localiza-se na mesorregião Norte de Minas, mas por estar mais a leste, faz divisa com a mesorregião do Jequitinhonha no nordeste do estado, pertencendo à bacia hidrográfica do Jequitinhonha. De acordo com o Diagnóstico Ambiental da Bacia do Rio Jequitinhonha, realizado pelo IBGE (1997), o município de Salinas possui características climáticas parecidas aos dos municípios semiáridos do vale do Jequitinhonha.

Segundo Nimer (1989) nessa porção do Nordeste, englobando parte do sudeste brasileiro, a participação de linhas de instabilidade é importante, uma vez que é baixa a frequência de atuação das descontinuidades polares vindas de sudoeste. Ferreira e Silva (2012) reforçam o caráter mais seco em um estudo acerca do clima da porção mineira da bacia do Jequitinhonha, o qual o município de Salinas está localizado (na área mais seca da bacia), levando a formação de vegetação predominantemente de caatinga.

Os totais anuais dos anos considerados válidos para cada estação podem ser verificados na figura 03, bem como uma breve classificação dos anos mais secos e chuvosos para esses municípios, tendo por base a variabilidade dos dados evidenciada pelo desvio padrão. Observa-se, conforme descrito, os maiores volumes de chuva sobre Arinos-MG e Formoso-MG, significativamente superior aos observados nas estações de Espinosa-MG e Carinhanha-BA. Devido ao grande número de falhas verificadas em algumas séries históricas, uma análise mais precisa que envolva a comparação ano a ano torna-se problemática, bem como técnicas de correção dos dados baseadas nas estações 
próximas. O período compreendido entre 1961 a 1974 coloca-se como um dos mais prejudicados pelo excesso de falhas.

O uso da técnica de elaboração e representação do "Box Plot" (figura 04) possibilitou a identificação de características da distribuição da precipitação para cada mês do ano para os oito municípios estudados. Destaca-se que a menor ou maior dispersão verificadas nos dados se relaciona a susceptibilidade desses valores aos desvios. Quanto mais dispersos os dados, maior será sua susceptibilidade a desvios e, consequentemente, quanto menos dispersos menor sua susceptibilidade. No geral, o conjunto dos dados destacaram bem as características pluviométricas dos climas tropicais, com período chuvoso alternado por período seco. O conjunto das estações teve como trimestre mais chuvoso os meses de novembro, dezembro e janeiro, enquanto o trimestre mais seco compreendeu os meses de junho, julho e agosto. A dispersão verificada no período úmido mostra-se superior a do período seco, apresentando valores menos dispersos. Essa constatação torna-se significativa na medida em que para os sistemas antrópicos a variabilidade no período úmido é mais crítica do que aquela verificada no período seco. Os maiores valores outliers foram identificados nos meses de dezembro e janeiro, com ocorrências de totais mensais de mais de $700 \mathrm{~mm}$ superiores ao valor central dado pela mediana, como observado no mês de janeiro para a estação de Montes Claros.

Fatores atmosféricos atuantes sobre a região destacam-se como principal causa das irregularidades na distribuição das chuvas durante o ano. Silva et al. (2017, p.38) apresentam que tais fatores estão "sujeitos a variações em sua trajetória e intensidade ao longo do tempo". Destaca-se aqui a ação de frentes frias, linhas de instabilidade, zonas de convergência de umidade (ZCOU), zona de convergência do atlântico sul (ZCAS), bem como a convecção tropical. Conforme os autores, para a região:

Nos períodos mais secos, a intensidade e frequência de atuação de sistemas de alta pressão, notadamente a ação do Anticiclone Subtropical do Atlântico Sul (ASAS), cuja subsidência do ar, reforçada pela atuação conjunta com a Célula de Walker, dificulta a ocorrência de precipitações (SILVA et al., 2017, p.38).

Kayano e Andreoli (2009, p.214) acerca da atuação do ASAS no território brasileiro, descrevem que o "ASAS intensifica-se com certa regularidade e avança sobre o país de leste para oeste, começando no final do verão do Hemisfério Sul (HS), atingindo sua máxima intensidade em julho e declinando até janeiro". 

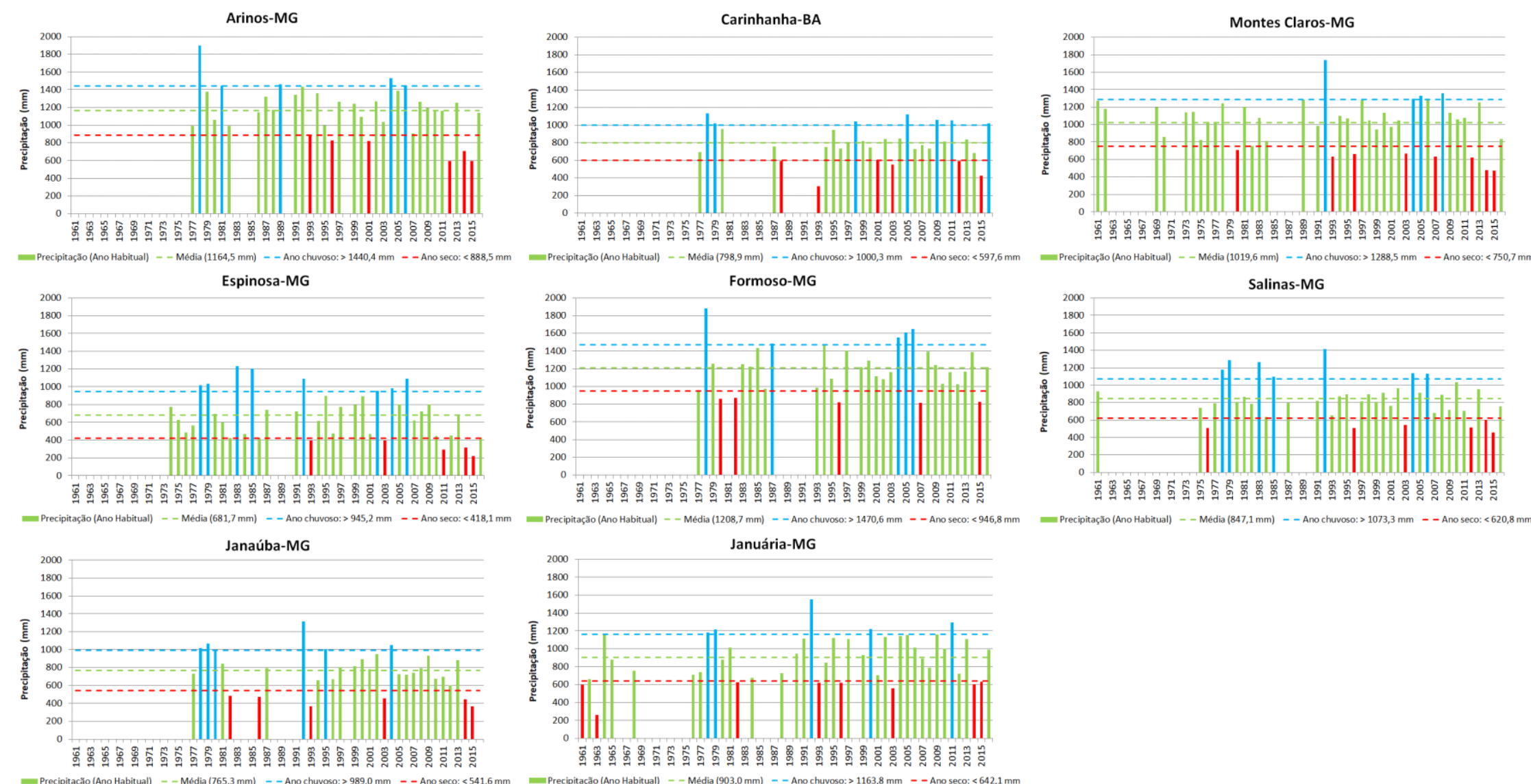

Figura 03 - Variação dos totais anuais de precipitação para os municípios de Arinos, Espinosa, Formoso, Janaúba, Januária, Montes Claros (MG) e Carinhanha (BA). Organização: Felipe Pereira de Moura. 

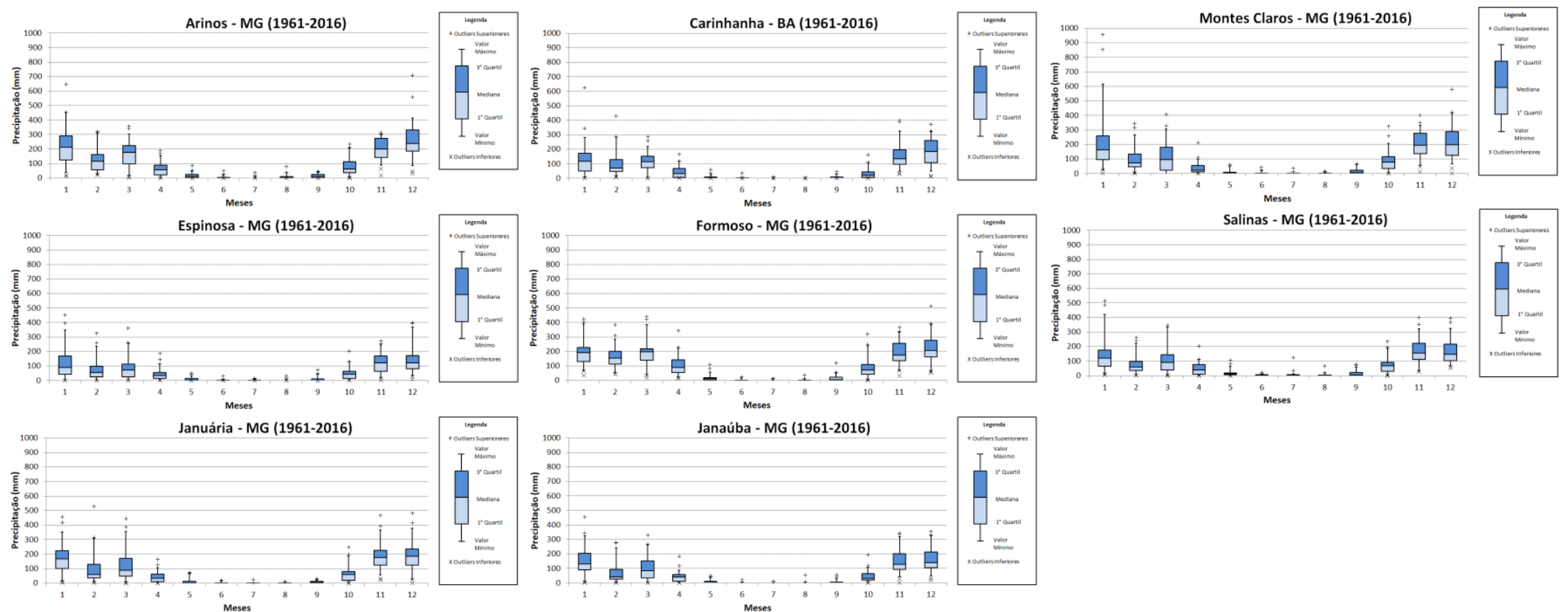

Figura 04 - Gráficos de distribuição dos totais mensais de precipitação através do "Box Plot" para os municípios de Arinos, Espinosa, Januária, Montes Claros, Formoso, Janaúba, Salinas (MG) e Carinhanha (BA). Organização: Felipe Pereira de Moura. 
O ASAS caracteriza-se como um sistema de alta pressão, com padrão de circulação marcado pela subsidência dinâmica do ar e sua divergência, tendo seu centro móvel situado na região tropical do oceano Atlântico no Hemisfério Sul. Em razão de sua atuação, que serve como bloqueio para o avanço dos sistemas frontais vindos de latitudes superiores, seu período de intensidade mais elevada coincide com o período de maior seca na porção norte de minas.

A classificação feita para cada mês com base nos valores mensais de precipitação verificados nas séries históricas permitiu, conforme a metodologia adotada, o enquadramento destes em cinco categorias, sendo elas: super seco, seco, normal, úmido e super úmido, conforme a figura 05.

\begin{tabular}{|c|c|c|c|c|c|c|}
\hline \multicolumn{7}{|c|}{ Arinos - MG } \\
\hline & S. Seco & Seco & Normal & Úmido & S. Úmido & Total \\
\hline \begin{tabular}{|l|} 
Meses \\
\end{tabular} & 14 & 142 & 148 & 92 & 24 & 420 \\
\hline$\%$ & $3,33 \%$ & $33,81 \%$ & $35,24 \%$ & $21,90 \%$ & $5,71 \%$ & $100 \%$ \\
\hline \multicolumn{7}{|c|}{ Espinosa - MG } \\
\hline & S. Seco & Seco & Normal & Úmido & S. Úmido & Total \\
\hline Meses & 12 & 160 & 165 & 107 & 24 & 468 \\
\hline$\%$ & $2,56 \%$ & $34,19 \%$ & $35,26 \%$ & $22,86 \%$ & $5,13 \%$ & $100 \%$ \\
\hline \multicolumn{7}{|c|}{ Januária - MG } \\
\hline & S. Seco & Seco & Normal & Úmido & S. Úmido & Total \\
\hline Meses & 14 & 182 & 163 & 109 & 24 & 492 \\
\hline$\%$ & $2,85 \%$ & $36,99 \%$ & $33,13 \%$ & $22,15 \%$ & $4,88 \%$ & $100 \%$ \\
\hline \multicolumn{7}{|c|}{ Montes Claros - MG } \\
\hline & S. Seco & Seco & Normal & Úmido & S. Úmido & Total \\
\hline Meses & 12 & 159 & 19 & 119 & 24 & 504 \\
\hline$\%$ & $2,38 \%$ & $31,55 \%$ & $37,70 \%$ & $23,61 \%$ & $4,76 \%$ & $100 \%$ \\
\hline
\end{tabular}

\begin{tabular}{|c|c|c|c|c|c|c|}
\hline \multicolumn{7}{|c|}{ Carinhanha - BA } \\
\hline & S. Seco & Seco & Normal & Úmido & s. Úmido & Total \\
\hline Meses & 12 & 142 & 111 & 71 & 24 & 360 \\
\hline$\%$ & $3,33 \%$ & $39,44 \%$ & $30,83 \%$ & $19,72 \%$ & $6,67 \%$ & $100 \%$ \\
\hline \multicolumn{7}{|c|}{ Formoso - MG } \\
\hline & S. Seco & Seco & Normal & Úmido & s. Úmido & Total \\
\hline Meses & 14 & 134 & 140 & 84 & 24 & 396 \\
\hline$\%$ & $3,54 \%$ & $33,84 \%$ & $35,35 \%$ & $21,21 \%$ & $6,06 \%$ & $100 \%$ \\
\hline \multicolumn{7}{|c|}{ anaúba - MG } \\
\hline & S. Seco & Seco & Normal & Úmido & S. Úmido & Total \\
\hline Meses & 14 & 143 & 116 & 75 & 24 & 372 \\
\hline$\%$ & $3,76 \%$ & $38,44 \%$ & $31,18 \%$ & $20,16 \%$ & $6,45 \%$ & $100 \%$ \\
\hline \multicolumn{7}{|c|}{ Salinas - MG } \\
\hline & S. Seco & Seco & Normal & Úmido & S. Úmido & Total \\
\hline Meses & 16 & 112 & 208 & 108 & 24 & 468 \\
\hline$\%$ & $3,42 \%$ & $23,93 \%$ & $44,44 \%$ & $23,08 \%$ & $5,13 \%$ & $100 \%$ \\
\hline
\end{tabular}

Figura 05 - Classificação dos meses (\%) em relação aos totais de precipitação das séries históricas analisadas para os municípios de Arinos, Espinosa, Formoso, Janaúba, Januária, Montes Claros - MG e Carinhanha - BA. Organização: Felipe Pereira de Moura.

De modo geral, os municípios analisados tiveram como classificação predominante de seus meses como normais ou secos. Arinos, Montes Claros e Formoso, que apresentaram as maiores médias de precipitação anual, também apresentaram a maior quantidade de meses classificados como normais seguidos por percentuais próximos aos meses secos. A estação de Espinosa teve percentuais muito próximos dos meses classificados como normais e secos, mesmo sendo a estação que apresentou os menores totais de chuva. A comparação entre essas estações destaca o fato de que a metodologia aplicada classifica o regime pluviométrico apresentado pelas séries de determinada estação, com base no próprio comportamento dos dados, e não por totais já estabelecidos.

O município que apresentou o maior percentual de meses classificados como normais foi Salinas, com um percentual de $44,44 \%$ dos meses nessa classe, seguidos pelos meses classificados como secos e úmidos, com percentuais similares, 23,93\% e 23,08\%, respectivamente. Essa classificação se deve a certa regularidade de ocorrência nessa localidade de pequenos totais de precipitação durante 0 período seco (associado aos baixos índices pluviométricos). Principalmente no inverno, quando na maior parte das estações 
verifica-se significativa quantidade de meses totalmente sem chuvas, a estação de Salinas apresenta pequenos índices de precipitação. Em razão de se situar a leste da Serra do Espinhaço, esse município sofre maior influência do que Nimer (1989) apresenta como "correntes perturbadas de E (leste)". Tal fenômeno, para o autor, pode ocasionar chuvas mais ou menos abundantes, tendo maior frequência durante o período do outono e inverno, afetando mais as regiões que vão desde o litoral do Rio Grande do Norte até o norte do estado do Rio de Janeiro, com diminuição significativa em seu avanço para o interior do continente, e, no caso de Minas Gerais, raramente ultrapassa a Serra do Espinhaço (NIMER, 1989). Deste modo, a atuação desse fenômeno acaba por diferenciar as características do período seco no município de Salinas do restante das estações.

Os municípios de Januária, Janaúba e Carinhanha tiveram em sua classificação o predomínio de meses secos, seguidos dos normais e úmidos. Carinhanha-BA foi 0 que apresentou a maior porcentagem de meses classificados como seco e o menor percentual de meses classificados como úmidos, destacando o caráter mais seco do município.

As observações realizadas para o conjunto das estações, se comparadas com análise similar aplicada em outras localidades, evidencia as características de seca na região. Silva et al. (2017), aplicando a mesma metodologia para os municípios de Belo Horizonte e Sete Lagoas, inseridos em contexto climático mais úmido, encontraram predomínio significativamente superior dos meses classificados como normais frente aos meses secos. Deste modo, destaca-se o aspecto mais seco da porção norte do estado de Minas Gerais, cuja ocorrência de meses secos é mais frequente, sugerindo maior influência da dinâmica do semiárido sobre a região.

Em relação às variações locais, restritas à bacia do rio Pandeiros, verificou-se valor superior na estação meteorológica de Chapada Gaúcha com $1028,9 \mathrm{~mm}$ e menor em Januária com 898,3 mm, fato também verificado na distribuição média mensal das chuvas nas duas localidades (figura 06), exceto no mês de novembro, comparando os totais médios anuais de chuva entre os anos de 2008 e 2017 (a estação da Chapada Gaúcha entrou em operação em 22/06/2007).

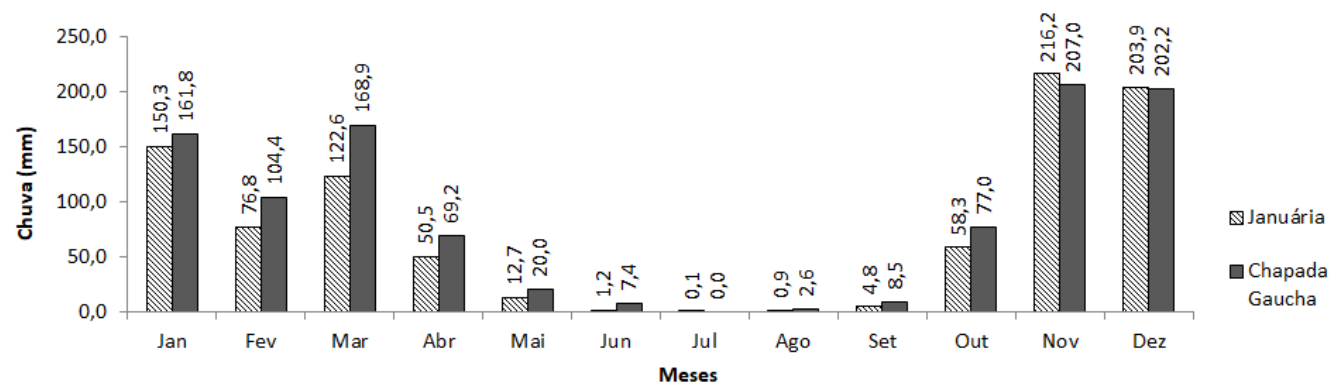

Figura 06 - Totais médios mensais de precipitação em Januária e Chapada Gaúcha (MG) para os anos entre 2008 e 2017 (Org.: Carlos H. Jardim).

A relativa proximidade entre as localidades (Januária/Chapada Gaúcha: $\pm 100 \mathrm{~km}$ ) permite situá-las sob mesmo domínio de influência das massas de ar. Entretanto, a topografia e altitude assumem o papel de modular localmente as 
variações de chuvas, aumentando a turbulência mecânica do ar pelo efeito da altitude no caso da estação da Chapada Gaúcha a 873 m (Januária encontra-se a $468 \mathrm{~m}$ ). O aumento da convecção do ar, acompanhado de resfriamento adiabático, favorece a formação de nuvens e precipitação (efeito orográfico).

Do ponto de vista ambiental, os totais mais elevados de chuva nos setores de maior altitude e declividades da bacia hidrográfica do rio Pandeiros contribuem de forma adicional para o desenvolvimento de processos erosivos, visíveis na forma de extensas voçorocas nesse setor da bacia.

\section{CONCLUSÕES}

A substituição da vegetação nativa biodiversa, dotada de diferentes ciclos fenológicos, por ecossistemas simplificados com espécies culturalmente valorizadas pelas sociedades humanas (lavouras, silvicultura, pastagens etc.), além da introdução de equipamento urbano, favorece o saldo positivo de calor, que é adicionado ao saldo positivo natural próprio das latitudes tropicais, forçando a elevação da temperatura do ar durante o dia, com forte perda radiativa noturna em função da relativa estabilidade atmosférica e baixo valor de umidade do ar.

A preservação de espaços com vegetação nativa é fundamental na pedogênese, preservação da microfauna do solo, infiltração de água de chuva, evaporação (via evapotranspiração dos vegetais) e regulação da vazão dos rios, ainda mais se for considerada as características de distribuição das chuvas quando comparado à outras regiões do território mineiro e do Brasil. Conforme pode ser verificado pela análise do Box Plot em relação à variabilidade desse atributo, a maior dispersão nos dados foi verificada justamente nos meses mais úmidos.

A compartimentação do clima mostrou-se semelhante àquela apresentada por Nimer (1989) e Sant'Anna Neto (2005), com redução dos totais de chuva de sul-sudoeste para norte-nordeste. O formato é similar ao observado na configuração dos sistemas frontais e na atuação das ZCOU e ZCAS, responsáveis por grande parte da ocorrência de precipitação na região sudeste (e no norte de Minas Gerais), incluindo, também, as instabilidades de oeste e noroeste no interior do continente, o que explica a ocorrência de totais mais elevados de precipitação nos municípios situados a oeste e a sul da porção norte do estado.

A classificação mensal dos dados de precipitação evidenciou tendência de maior frequência de meses secos e normais sobre a região, sugerindo padrão relacionado mais estreitamente ao regime seco de chuvas, com características de transição entre o clima tropical semiúmido e o tropical semiárido.

Em relação às variações locais de chuva na bacia do rio Pandeiros, como foi visto, a distribuição é diferenciada e favorece as áreas mais elevadas sobre os chapadões a oeste, o que impõe necessidade de restrição parcial/total de uso na área de contato com a chapada, expostas ao maior índice de chuvas, em função da elevada declividade e propensão ao desenvolvimento de processos erosivos, podendo amplificar a carga de sedimentos e assoreamento na foz do rio Pandeiros. 


\section{AGRADECIMENTOS}

À Fundação de Amparo à Pesquisa do Estado de Minas - FAPEMIG (Projeto APQ-03773-14 - Sustentabilidade da bacia do Rio Pandeiros-MG: Dinâmica de vertentes da bacia do rio Pandeiros, aprovado em dezembro de 2014) e ao Conselho Nacional de Desenvolvimento Científico e Tecnológico (CNPq) pela concessão de bolsa de mestrado.

\section{REFERÊNCIAS}

ARYA, S. P. Introduction to Micrometeorology. 2.ed. San Diego-USA: Academic Press, 2001.

ASSIS, W. L. O sistema clima urbano do município de Belo Horizonte na perspectiva têmporo-espacial. Tese (Doutorado em Geografia) - Departamento de Geografia - Instituto de Geociências - Universidade Federal de Minas Gerais, Belo Horizonte, 2010.

AVILA, M. R. R; MATTEDI, M. A. As dimensões políticas da produção de desastres: o caso do território do Vale do Itajaí/SC. Disponível em: <https://online.unisc.br/acadnet/anais/index.php/sidr/article/viewFile/13308/24 74> Acesso: 14 ago. 2018.

AYOADE. J. O. Introdução à climatologia para os trópicos. $15^{a}$ ed. Rio de Janeiro: Ed. Bertrand, 2011.

AZEVEDO, T. R; TARIFA, J. R. O ritmo semanal das atividades humanas e o clima na região metropolitana de São Paulo. Geousp, n.9, p.9-35, 2001.

BORSATO, V. C. A dinâmica climática do Brasil e massas de ares. 1. Ed. Curitiba, PR: CRV, 2016.

CONTI, J. B. Resgatando a "fisiologia da paisagem". Revista do Departamento de Geografia, n.14, p. 59-68, 2001.

DNMET. Departamento Nacional de Meteorologia. Normais Climatológicas (19611990). Brasília-DF, 1992.

EMBRAPA - Empresa Brasileira de Pesquisa Agropecuária. Serviço Nacional de Levantamento e Conservação de Solos. Levantamento ExploratórioReconhecimento de Solos do Norte de Minas Gerais (Área de atuação da SUDENE). (Boletim Técnico, 60), Recife, p.407, 1979.

FERREIRA, V. O; SILVA, M. M. O Clima da Bacia do Rio Jequitinhonha, em Minas Gerais: Subsídios para a Gestão de Recursos Hídricos. Revista Brasileira de Geografia Física, v. 5, p. 302-319, 2012.

FERNANDEZ, M. N. Preenchimento de Falhas em Séries Temporais. 2007. 106p. (Dissertação de Mestrado em Engenharia Oceânica) - Fundação Universidade Federal do Rio Grande, Rio Grande, 2007.

GALVANI, E; LIMA, N. G. B; ALVES, R. R. Variabilidade e tendência das precipitações no litoral sul de São Paulo. Revista GEONORTE, Edição Especial 2, v.1, n.5, p.1163-1176, 2012.

GALVANI, E.; LUCHIARI, A. Critérios para a classificação de anos com regime pluviométrico normal, seco e úmido. In. GALVANI, E.; LIMA, N. G. B. (Orgs.) Climatologia aplicada: resgate aos estudos de caso. 1ed. Curitiba: CRV, 2012. 
GEIGER, R. Manual de microclimatologia. O clima da camada de ar junto ao solo. 4.ed. Lisboa: Fundação Calouste Gulbenkian, 1961.

IBGE - INSTITUTO BRASILEIRO DE GEOGRAFIA E ESTATÍSTICA. Cidades. Disponível em: <http://www.cidades.ibge.gov.br/xtras/home.php> Acesso: 20 jul. 2016.

IBGE - INSTITUTO BRASILEIRO DE GEOGRAFIA E ESTATÍSTICA. Diagnóstico Ambiental da Bacia do Rio Jequitinhonha. 1997. Disponível em: <http://www.ibge.gov.br/home/geociencias/recursosnaturais/diagnosticos_leva ntamentos/> Acesso: 07 jan. 2017.

JARDIM, C. H; SILVA, M. R. Extremos de temperatura do ar em Belo Horizonte: variabilidade natural e influência do clima urbano. Revista do Departamento de Geografia, Volume Especial, p.83-97, 2016.

JARDIM, C. H. Aspectos teórico-metodológicos relativos à dimensão temporal e espacial do clima. Geografias, vol.14, n.1, p.82-95, 2017.

KAYANO, M. T.; ANDREOLI, R. V. Clima da Região Nordeste do Brasil. In: Cavalcanti, I. F. A.; Ferreira, N.J.; Silva, M. G. A. J.; Dias M. A. F. S. (Org.). Tempo e Clima no Brasil. 1ed. São Paulo: Oficina de Textos, 2009, v. 1, p. 213233.

MOLION, L.C.B. Aquecimento global, El Niños, manchas solares, vulcões e oscilação decadal do Pacífico. Revista Climanálise, ano 3, n.1, ago. 2005.

MONTEIRO, C. A. F. Análise rítmica em climatologia. Problemas da atualidade climática em São Paulo e achegas para um programa de trabalho. Climatologia, São Paulo, n.01, p.1-21, 1971.

MONTEIRO, C. A. F. Derivações Antropogenéticas dos Geossistemas no Brasil e Alterações Climáticas. Perspectivas urbanas e agrárias ao problema da elaboração de modelos de avaliação. In: SIMPÓSIO ACADEMIA DE CIÊNCIAS DO ESTADO DE SÃO PAULO. São Paulo. A Comunidade Vegetal como unidade biológica, turística e econômica. Anais... São Paulo: Aciesp, 1978, p.43-76.

MONTEIRO, C. A. F. Geossistemas: a história de uma procura. São Paulo: Contexto, 2000.

NIMER, E. Climatologia do Brasil. 2.ed., Rio de Janeiro: IBGE, 1989.

SANT'ANNA NETO, J.L. Decálogo da climatologia do sudeste brasileiro. In: Revista Brasileira de Climatologia, v.1, n.1, dez./2005.

SANTOS, R. M. dos; VIEIRA, F. A.; FAGUNDES, M.; NUNES, Y. R. F.; GUSMÃO, E.; Riqueza e similaridade florística de oito remanescentes florestais no Norte de Minas Gerais, Brasil. Revista Árvore, v. 31, p. 135-144, 2007.

SILVA, M. R.; Moura, F. P.; JARDIM, C. H. O diagrama de Caixa (Box Plot) Aplicado à Análise da Distribuição Temporal das Chuvas em Januária, Belo Horizonte e Sete Lagoas, Minas Gerais-Brasil. Revista Brasileira de Geografia Física, v. 10, p. 15-35, 2017.

STEINKE, E. T. Considerações sobre variabilidade e mudança climática no distrito federal, suas repercussões nos recursos hídricos e informação ao grande público. Brasília-DF, 2004. 216 f. Tese (Doutorado) Departamento de Ecologia, Universidade de Brasília, 2004. 
TARIFA, J. R.; ARMANI, G. Os climas "naturais". In: TARIFA, J. R.; AZEVEDO, T. R. (Orgs.) Os climas na cidade de São Paulo: teoria e prática. São Paulo: PróReitoria de Cultura e Extensão. Universidade de São Paulo: Laboratório de Climatologia. Faculdade de Filosofia, Letras e Ciências Humanas. Universidade de São Paulo, 2001a. Cap. 2. p. 34-46. (Geousp - Coleção Novos Caminhos, 4).

TARIFA, J. R.; ARMANI, G. Os climas urbanos. In: TARIFA, J. R.; AZEVEDO, T. R. (Orgs.) Os climas na cidade de São Paulo: teoria e prática. São Paulo: PróReitoria de Cultura e Extensão. Universidade de São Paulo: Laboratório de Climatologia. Faculdade de Filosofia, Letras e Ciências Humanas. Universidade de São Paulo, 2001b. Cap. 3. p. 47-70. (Geousp - Coleção Novos Caminhos, 4).

VIANELLO, R. L; SEDIYAMA, G. C; FERNANDES, A. S; GEMIACKI, L. Variabilidades climáticas e seus impactos na agricultura de Minas Gerais. Informe Agropecuário, Belo Horizonte, v.29, n.246, p.19-36, set./out. 2008. 